\title{
Community Empowerment and the Associated Factors among the 2014 Flood Victims in Pahang
}

\author{
Rozita Hod ${ }^{1}$, Humadevi Sivasamy ${ }^{1}$, Sharifa Ezat Wan Puteh ${ }^{1, *}$, Azmawati Mohammed Nawi ${ }^{1}$, \\ Idayu Badilla Idris ${ }^{1}$, Izzah Syazwani Ahmad ${ }^{1}$, Chamhuri Siwar ${ }^{2}$, Mohd Raihan Taha ${ }^{2}$ \\ ${ }^{1}$ Department of Community Health, Faculty of Medicine, University Kebangsaan Malaysia, Malaysia \\ ${ }^{2}$ Institute for Environment and Development (LESTARI), University Kebangsaan Malaysia, Malaysia
}

Copyright $\mathrm{O} 2017$ by authors, all rights reserved. Authors agree that this article remains permanently open access under the terms of the Creative Commons Attribution License 4.0 International License

\begin{abstract}
Community empowerment plays an important role in adapting and preparing towards flood risks and impacts. The flood which occurred in 2014 had severely affected three states in the east coast of Peninsular Malaysia and left a significant mark on the communities residing in those areas. A cross sectional study was conducted in 2015 by distributing a validated semi guided questionnaires among flood victims in three worst affected districts in Pahang. The objective was to assess the status of community empowerment and its associated factors. The Individual Community Related Empowerment (ICRE) tool was used to assess the community empowerment. A total of 602 respondents participated in this study. The majority of the respondents were males of Malay ethnic, residing in rural villages. Their ages ranged from 19 to 88 years old, with an average age of 48 years old. The community empowerment domains in our study were self-efficacy, intention, participation, motivation and critical awareness. Younger age was associated with higher self-efficacy. Males were found to have higher participation and motivation. Those who experienced more health symptoms were positively significantly correlated with all domains of empowerment except for self-efficacy. In conclusion, low status of empowerment is seen in all domains except for motivation and critical awareness.
\end{abstract}

Keywords Flood, Health Impacts, Community Empowerment

\section{Introduction}

Flood is one of the most common environment and climate-related event in Malaysia.[1,2] Due to the geographical complexity in Malaysia, such phenomenon is due to either natural causes, or cyclical monsoons during the local tropical wet season, usually at the end of the year. These monsoon seasons bring heavy and prolonged rainfall coupled with poor coping capacity of the particular area in handling the large amount of rain output. Among the other conditions that may contribute to flood are tropical storms, breakage of embankment levees, clogged drainage systems and rapid accumulation of heavy rainfall. [3] Numerous states in Malaysia are annually affected by the heavy rainfall during the monsoon season from the month of October to March. In Malaysia, the states that are usually affected are Perlis, Kedah, Perak, Johor, Pahang, Kelantan, Terengganu, Sabah and Sarawak [4]

The year 2014 saw Malaysia being hit by one of the worst flooding in recent decade. From 15th of December 2014 to 3rd of January 2015 [5] nearly 200,000 people were affected in the state of Kelantan alone. [6] The flood was seemingly attributed to the coinciding events of heavy rainfall due to the northeast monsoon and high tide from South China Sea. In the state of Pahang, the worst affected places were areas from Pekan, Lipis, Jerantut, Maran, Temerloh and Kuantan. The unprecedented massive floods were mainly due to the continuous rapid rise in water volume and the level of the Pahang and Kuantan Rivers.

When floods happen, the general effects would include loss of life, buildings and infrastructure damage such as bridges, motorways, railroads and the drainage as well as the sewerage systems. In the Malaysian 2014 flooding, the primary effect also included electrical power shutdown and loss of drinking water treatment plants. Most of the roads connecting to the affected areas were either damaged, almost washed away, or closed, becoming totally inaccessible by public at large. Urgent aid such as essential medicines, food, clean water and logistic supply were severely hampered and deprived the locals of their urgently needed assistance and medical emergency health treatment. [7]

The impact of flood depends on the local geographical landscape as well as the vulnerability of the affected community. [8] Immediate or short term effects within the first month of flooding may be death or drowning, [9-11] injury, toxic exposure [12] and spread of infectious diseases, especially water-borne diseases such as typhoid, hepatitis, 
leptospirosis, cholera and food poisoning. [13-15] Long-term effects that occurred months after the flood event, are non-communicable diseases, malnutrition, [16] anxiety, [17] Post-Traumatic Stress Disorder (PTSD) [18] or depression.

Community empowerment represents a core concept in reducing health inequalities and achieving a better quality of life. Previous studies have proved that the communities' preparedness can mitigate the impact of disaster. [19-20] Community empowerment is an important part of capacity development where its community members decide on the goals and strategies for disaster risk management, contribute some, if not all, of the resources needed, and monitor their performance. [21]

Several factors determine the involvement of the community. The socio-demographic (age, gender, strata-urban or rural, ethnicity, religion, marital status, level of education, household income) and health impact factors (underlying comorbidities, health symptoms experienced post flood, access to nearest health facility) have great influence on the society's empowerment characteristics.

Therefore, identifying the effects of these factors among flood prone community would provide an insight of the relationship between the flood hazards and community. This can further facilitate the planning and implementation of the empowerment programs. [22] Hence the susceptibility to the effects of future flood can be reduced.

By empowering communities to develop solutions to flooding, a self-sustainable, replicable non-government mechanism for disaster mitigation and preparedness can be accomplished. This can be achieved by providing communities with a higher degree of security from natural disasters, training local village volunteers in disaster preparedness concepts and techniques, establishing local disaster community and mobilizing funds to self-empower these communities.

In view of this, the main objective of this study was to assess the community empowerment status towards dealing with flood disasters, its associated factors, and provide recommendations for improvement. It was further hypothesized that there are significant association between socio-demographic factors of the affected people and their health impact with level of empowerment in different domains.

\section{Materials and Methods}

\subsection{Study Area and Design}

A cross sectional study was conducted between May to September 2015 in the state of Pahang, Malaysia. In this cross sectional study or another term, a prevalence study, the data obtained was analyzed from the flood victims in Pahang, at a specific point in time.

\subsection{Selection of Study Population}

During the worst flood period in year 2014, the districts of Pekan, Kuantan and Temerloh in Pahang were badly affected. From these districts, a total of 602 flood victims above 18 years old participated in this research. Sample size calculation was done using Pocock formula and sample size 602 was derived. The respondents were selected via stratified random sampling method, obtained from the database in the District Administrative Office.

\subsection{Data Collection}

Data for this research were collected using semi guided questionnaire. Written consent was obtained from the respondents prior to application of the questionnaire. The Individual Community-Related Empowerment (ICRE) questionnaire was in the Malay language and has been validated by our research team. The dependent variable was community empowerment. Community empowerment was defined as a process where communities, organizations and/or individuals were enabled to assume the power to act effectively to change their lives. The questionnaire consisted of 18 items rated on a Likert-type five point scale ( $1=$ 'strongly disagree', to $5=$ 'strongly agree'). The five domains of ICRE were self-efficacy, intention, participation, motivation and critical awareness. Self-efficacy was related to an individual's attitude toward social change in community which consisted of 7 items; intention was defined as the plan to become involved in community change and this domain consisted of 4 items; participation was defined as taking part in community activities and this domain had 3 items; motivation to be involved was defined as the reason for the actions taken and this domain consisted of 3 items; critical awareness was defined as examination of ideas using reasoning to arrive at a conclusion, and in this study, awareness that community issues are serious and this domain consisted of 1 item. [18]. A copy of the questionnaire used has been appended to this article.

\subsection{Statistical Analysis}

Descriptive and statistical analytical tests were computed using 'Statistical Package for Social Science' (SPSS) Version 23.0. The $p$ value $<0.05$ was taken as the statistical significance level.

\subsection{Ethical Consideration}

Approval from the Medical Research and Ethics Committee, Universiti Kebangsaan Malaysia was also obtained. (Project code: FF-2015-359)

\section{Results}

The socio-demographic characteristics of the respondents 
were measured in eight different domains, which were the independent variables shown in Table 1. Majority $(58.6 \%)$ of the respondents ranged from 41 to 65 years old with an overall mean age of 48 (SD13.2) years. More than half of the total respondents $(55.3 \%)$ were from the rural area compared to their urban counterpart. Predominantly male respondents were higher $(63.8 \%)$ compared to female (36.2\%) respectively (Table 1$)$.

The mainstream respondents from this research were low income earners with a household income of less than USD 906.93. From this group, nearly $40 \%$ of them earned less than USD 226.73 and $3.2 \%$ of them did not have any active income (Table 1).

Table 1. Distribution of socio-demographic characteristics of respondents

\begin{tabular}{|c|c|c|}
\hline Characteristics $(n=602)$ & Frequency (n) & Percent (\%) \\
\hline \multirow{2}{*}{\multicolumn{3}{|c|}{$\begin{array}{c}\text { Age (Years) } \\
\text { Mean (Std dev) }=48.0(13.2)\end{array}$}} \\
\hline & & \\
\hline $18-40$ & 182 & 30.3 \\
\hline $41-65$ & 353 & 58.6 \\
\hline 66 and above & 67 & 11.1 \\
\hline \multicolumn{3}{|l|}{ Strata } \\
\hline Urban & 269 & 44.7 \\
\hline Rural & 333 & 55.3 \\
\hline \multicolumn{3}{|l|}{ Gender } \\
\hline Male & 384 & 63.8 \\
\hline Female & 218 & 36.2 \\
\hline \multicolumn{3}{|l|}{ Ethnicity } \\
\hline Malay & 589 & 97.8 \\
\hline Chinese & 4 & 0.7 \\
\hline Indian & 2 & 0.3 \\
\hline Orang Asli & 2 & 0.3 \\
\hline Others & 5 & 0.9 \\
\hline \multicolumn{3}{|l|}{ Religion } \\
\hline Islam & 598 & 99.4 \\
\hline Hindu & 2 & 0.3 \\
\hline Buddha & 2 & 0.3 \\
\hline \multicolumn{3}{|l|}{ Marital Status } \\
\hline Single & 31 & 5.1 \\
\hline Married & 484 & 80.4 \\
\hline Divorced & 10 & 1.7 \\
\hline Widowed & 76 & 12.6 \\
\hline Not answered & 1 & 0.2 \\
\hline \multicolumn{3}{|l|}{ Level of Education } \\
\hline Never Schooled & 17 & 2.8 \\
\hline Primary School & 147 & 24.4 \\
\hline SRP/PMR & 115 & 19.1 \\
\hline SPM & 245 & 40.7 \\
\hline STPM/Diploma & 36 & 6.0 \\
\hline Vocational & 3 & 0.5 \\
\hline Degree or higher & 38 & 6.3 \\
\hline Not Answered & 1 & 0.2 \\
\hline \multicolumn{3}{|l|}{ Household Income } \\
\hline (RM/Month) & 19 & 3.2 \\
\hline No Income & 240 & 39.9 \\
\hline $\begin{array}{c}<\text { RM } 1000 \\
\text { RM } 1001 \text { - RM } 2000\end{array}$ & 201 & 33.4 \\
\hline $\begin{array}{l}\text { RM } 1001 \text { - RM } 2000 \\
\text { RM } 2001 \text { - RM } 3000\end{array}$ & 67 & 11.1 \\
\hline $\begin{array}{l}\text { RM } 2001 \text { - RM } 3000 \\
\text { RM } 3001 \text { - RM } 4000\end{array}$ & 38 & 6.3 \\
\hline $\begin{array}{c}\text { RM } 3001-\text { RM } 4000 \\
>\text { RM } 4001\end{array}$ & 37 & 6.1 \\
\hline
\end{tabular}

Table 2 shows the concurrent medical illnesses of the respondents. The majority suffered from hypertension (11\%) followed by diabetes mellitus (7.3\%) and arthritis $(3.8 \%)$.
The other types of illnesses (7\%) were asthma, low blood pressure and anemia. The comorbidities prior to flood and at the time of survey were almost the same.

Table 2. Distribution of type of concurrent medical illnesses among the respondents

\begin{tabular}{|c|c|c|}
\hline \multirow{2}{*}{ Characteristics (n=602) } & \multicolumn{2}{|c|}{ Frequency (Percent, n (\%)) } \\
\cline { 2 - 3 } & At Present & Prior Flood \\
\hline Type of Concurrent Medical & & \\
Illnesses & $67(11.1)$ & $66(11.0)$ \\
Hypertension & $44(7.3)$ & $43(7.1)$ \\
Diabetes Mellitus & $19(3.2)$ & $19(3.2)$ \\
Heart Disease & $11(1.8)$ & $10(1.7)$ \\
Nerve & $23(3.8)$ & $24(4.0)$ \\
Arthritis & $12(2.0)$ & $13(2.2)$ \\
Gout & $42(7.0)$ & $44(7.3)$ \\
Others & \\
\hline
\end{tabular}

As the gravity of the devastating flood in Pekan, Kuantan and Temerloh district increased, the health symptoms experienced by the respondents were inquired 2 weeks after the flood. A total of 21 symptoms were identified and it ranged from general symptoms, gastroenteritis related symptoms, respiratory symptoms, allergies and trauma. Majority of the symptoms were related to Upper Respiratory Tract Infections (URTI). Most of the respondents had developed fever (39.5\%), cough $(47.2 \%)$ and sore throat $(29.9 \%)$. Other cases which needed urgent interventions like chest pain (3.2\%) and shortness of breath $(3.0 \%)$ (Table 3$)$ were also encountered.

The distance in kilometer $(\mathrm{km})$ from the respondents' home to the nearest health facility was the minimum at 1 $\mathrm{km}$ and the maximum at $45 \mathrm{~km}$. The respondent could reach the health facility within 2 minutes to a maximum of 60 minutes.

Table 3. Distribution of respondents' health symptoms 2 weeks after flood

\begin{tabular}{|c|c|c|}
\hline Characteristics (n=602) & Frequency (n) & Percent (\%) \\
\hline Health Symptoms 2 Weeks After & & \\
Flood & & \\
Cough & 84 & 47.2 \\
Flu & 257 & 42.7 \\
Normal fever & 238 & 39.5 \\
Sore throat & 180 & 29.9 \\
Headache & 142 & 23.6 \\
Muscle pain & 107 & 17.8 \\
Itchiness of skin & 97 & 16.1 \\
Skin rashes & 54 & 9.0 \\
Loss of Appetite & 51 & 8.5 \\
Loss of weight & 47 & 7.8 \\
Diarrhea & 36 & 6.0 \\
Prolonged fever & 35 & 5.8 \\
Small injury & 28 & 4.7 \\
Chest pain & 19 & 3.2 \\
Vomiting & 18 & 3.0 \\
Shortness of breath & 18 & 3.0 \\
Lesion or skin infections & 6 & 1.0 \\
Urinary pain & 5 & 0.8 \\
Jaundice & 3 & 0.5 \\
Big injury & 3 & 0.5 \\
Accidents & 2 & 0.3 \\
Median = 3, IQR $=4$ & &
\end{tabular}

*IQR Inter Quartile Range 
Table 4 and Table 5 show the results of bivariate analysis performed between the independent and dependent variables. The exploratory analysis concluded that a few data are not normally distributed. Thus parametric and non-parametric tests were conducted for the relevant variables. The significant value chosen was $\mathrm{p}<0.05$ at the $95 \%$ Confidence Interval and study power of $80 \%$.

One of the five domains in community empowerment that we analyzed was self-efficacy. Self-efficacy is an individual's confidence in their capability in dealing with situations in the community. This was found to be negatively correlated with age $(\mathrm{r}=-0.1, \mathrm{p}=0.014)$. Younger respondents had higher self-efficacy compared to the older ones.

The second domain analyzed was intention. Intention is defined as the plan to become involved in community change. It was significantly associated with health symptoms experienced by the respondents as well as their education level. (Kruskal Wallis Test) $\mathrm{H}=6.042, \mathrm{p}=0.049$. The mean rank was 391 for those who were never schooled, 301.9 for those who attended school, and 278.9 for those with Sijil Tinggi Pelajaran Malaysia or STPM (the equivalent to GCE 'A' level) or higher. Health symptoms had significant positive correlation with domain intention with $\mathrm{rs}=0.183, \mathrm{p}<0.001$. Thus, the more health symptoms being experienced by the respondents, the higher their intention is.

Domain on participation is significantly associated with gender and rural strata. The male gender was more participative than the female counterparts ((Wilcoxon Rank Sum Test) $U=37132, p=0.020$ ). The rural community had higher participation than the urban community $(\mathrm{U}=40017$, $\mathrm{p}=0.023$ ). Distance to the nearest health facility showed significant positive correlation with participation ( $\mathrm{rs}=0.1$, $\mathrm{p}=0.014)$ and health symptoms also showed significant positive correlation with domain participation $(\mathrm{rs}=0.159$, $\mathrm{p}<0.001$ ). The participation was higher when it was longer to reach the nearest health facility and the more health symptoms experienced.

Domain on motivation is significantly associated with gender $(t=2.222, p=0.027)$. The males were more motivated than females. Distance to nearest health facility showed significant positive correlation with motivation $(\mathrm{rs}=0.104$, $\mathrm{p}=0.011$ ) and health symptoms also showed significant positive correlation with domain motivation ( $\mathrm{rs}=0.131$, $\mathrm{p}=0.001)$. The motivation was higher when the longer it took to reach the nearest health facility and the more health symptoms experienced.

Distance to nearest health facility showed significant positive correlation with critical awareness ( $\mathrm{rs}=0.194$, $\mathrm{p}<0.001$ ) and health symptoms also showed significant positive correlation with domain critical awareness ( $\mathrm{rs}=0.127, \mathrm{p}=0.002)$. The critical awareness was higher in those who experienced more health symptoms and when it took longer to reach the nearest health facility.

As for the empowerment domains, the mean (SD) and median for self-efficacy, intention, participation, motivation and critical awareness were 22.76 (SD5.88), 23; 14.75 (SD3.36), 16; 10.67 (SD3.35), 11; 11.04 (SD2.56), 11; and 2.54 (SD1.31), 2 respectively. The assumption made was, if the average score is less than the median score, this is considered as low empowerment. If the average score is higher than the median, then this is considered as high empowerment. Based on this, low status of empowerment was observed in all the domains except for motivation and critical awareness. 
Table 4. Summary of significant association between socio-demographic factors and domains of empowerment

\begin{tabular}{|c|c|c|c|c|c|c|c|c|c|c|c|c|c|c|c|c|c|c|}
\hline \multirow{2}{*}{$\begin{array}{c}\text { Characteristics } \\
n=602\end{array}$} & \multicolumn{4}{|c|}{ Self-efficacy } & \multicolumn{3}{|c|}{ Intention } & \multicolumn{3}{|c|}{ Participation } & \multicolumn{4}{|c|}{ Motivation } & \multicolumn{4}{|c|}{ Critical Awareness } \\
\hline & Mean & SD & Test & $\mathbf{p}$ & & Test & $\mathbf{p}$ & & Test & $\mathbf{p}$ & Mean & SD & Test & $\mathbf{p}$ & Mean & SD & Test & $\mathbf{p}$ \\
\hline \multicolumn{19}{|l|}{ Gender } \\
\hline Male & 23.0 & 5.9 & $1.171^{\mathrm{a}}$ & 0.242 & $308.40^{\mathrm{g}}$ & $39207^{b}$ & 0.188 & $313.80^{\mathrm{g}}$ & $37132 * b$ & 0.020 & 11.2 & 2.5 & $2.222^{* a \mathrm{a}}$ & 0.027 & 2.6 & 1.4 & $1.166^{\mathrm{a}}$ & 0.244 \\
\hline Female & 22.4 & 5.9 & & & $289.35^{\mathrm{g}}$ & & & $279.83^{\mathrm{g}}$ & & & 10.7 & 2.7 & & & 2.5 & 1.2 & & \\
\hline \multicolumn{19}{|l|}{ Strata } \\
\hline Urban & 23.3 & 5.3 & $1.962^{\mathrm{a}}$ & 0.050 & $292.58^{\mathrm{g}}$ & $42390^{\mathrm{b}}$ & 0.249 & $283.76^{\mathrm{g}}$ & $40017^{* b}$ & 0.023 & 10.8 & 2.4 & $-1.786^{\mathrm{a}}$ & 0.075 & 2.6 & 1.2 & $1.257^{\mathrm{a}}$ & 0.209 \\
\hline Rural & 22.4 & 6.3 & & & $308.70^{\mathrm{g}}$ & & & $315.83^{g}$ & & & 11.2 & 2.7 & & & 2.5 & 1.4 & & \\
\hline \multicolumn{19}{|l|}{ Education } \\
\hline Never Schooled & 24.8 & 5.8 & $1.420^{\mathrm{c}}$ & 0.242 & $391^{\mathrm{g}}$ & $6.042 * \mathrm{~d}$ & 0.049 & $362.8^{\mathrm{g}}$ & $4.138^{\mathrm{d}}$ & 0.126 & 11.9 & 2.0 & $1.293^{\mathrm{c}}$ & 0.275 & \multicolumn{2}{|c|}{$304.8^{\mathrm{g}}$} & $0.636^{\mathrm{d}}$ & 0.728 \\
\hline Primary /\& Secondary School & 22.6 & 5.9 & & & $301.9^{\mathrm{g}}$ & & & $303.5^{\mathrm{g}}$ & & & 11.1 & 2.5 & & & \multicolumn{2}{|c|}{$303.6^{\mathrm{g}}$} & & \\
\hline STPM or higher & 23.2 & 5.8 & & & $278.9^{\mathrm{g}}$ & & & $274.6^{\mathrm{g}}$ & & & 10.8 & 2.9 & & & \multicolumn{2}{|c|}{$287.1^{\mathrm{g}}$} & & \\
\hline
\end{tabular}

a Independent T test; b Wilcoxon Rank Sum Test; c ANOVA; d Kruskal Wallis Test; g Mean rank; *significant $\mathrm{p}<0.05$; ** significant $\mathrm{p}<0.01$

Table 5. Summary of significant correlation between socio-demographic factors and health symptoms of respondents 2 weeks after flood with domains of empowerment

\begin{tabular}{|c|c|c|c|c|c|c|c|c|c|c|}
\hline \multirow[t]{2}{*}{ Characteristics $n=602$} & \multicolumn{2}{|c|}{ Self-efficacy } & \multicolumn{2}{|c|}{ Intention } & \multicolumn{2}{|c|}{ Participation } & \multicolumn{2}{|c|}{ Motivation } & \multicolumn{2}{|c|}{ Critical Awareness } \\
\hline & Test & p & Test & $\mathbf{p}$ & Test & $\mathbf{p}$ & Test & p & Test & $\mathbf{p}$ \\
\hline Age & $-0.100 * \mathrm{e}$ & 0.014 & $0.013^{\mathrm{f}}$ & 0.743 & $0.036^{\mathrm{f}}$ & 0.373 & $0.038^{\mathrm{e}}$ & 0.349 & $-0.005^{\mathrm{e}}$ & 0.897 \\
\hline $\begin{array}{c}\text { Distance to nearest health } \\
\text { facility (minute) }\end{array}$ & $0.056^{\mathrm{f}}$ & 0170 & $0.055^{\mathrm{f}}$ & 0.180 & $0.100^{* \mathrm{f}}$ & 0.014 & $0.104 * \mathrm{f}$ & 0.011 & $0.194 * * \mathrm{f}$ & 0.000 \\
\hline $\begin{array}{c}\text { Respondent's health symptoms } \\
\text { 2 weeks after flood }\end{array}$ & $0.054^{\mathrm{f}}$ & 0.189 & $0.183^{* * \mathrm{f}}$ & 0.000 & $0.159 * * \mathrm{f}$ & 0.000 & $0.131 * * \mathrm{f}$ & 0.001 & $0.127 * * \mathrm{f}$ & 0.002 \\
\hline
\end{tabular}

e Pearson Correlation; f Spearman Correlation;

*significant $\mathrm{p}<0.05$; **significant $\mathrm{p}<0.01$ 


\section{Discussion}

The main findings of this study showed significant association of age, rural strata, gender, education level, wellness and health access of the community with the different domains of empowerment. The younger the community is, the higher their self-efficacy is. The more health symptoms experienced, the higher their intention. Those from the rural areas, the men, and those who stayed a greater distance from the health facilities showed higher level of participation. There was a relatively high empowerment for the domain motivation and critical awareness.

Self-efficacy is an individual's confidence in their capability in dealing with situations in the community and their attitude towards social change. The younger generation in this study showed higher self-efficacy because they are dynamic and constantly exposed to information via mass media and technology. The information and education obtained on flood risk information escalates their self-efficacy. [23]. On the contrary, a study conducted by Thapa \& Gurung, 2010, showed that the empowerment level increases with age of the women and that the older adults were emotionally resilient. [24]

Other studies however, showed age is unrelated to empowerment and it depends on individual response. [25]

Nevertheless, we believe that education can promote empowerment. Education in general enhances the cognition, learning and coping skills of the individual and increases access to information. [29] Knowledge on disaster management particularly helps improve community empowerment. [23, 30-32] Education level also has significant association with participation in economic activities among women and thus facilitates the empowerment in women. In accordance to this, this study observed significant association of education with domain intention to participate, which can strengthen the community empowerment.

The impact of any major flood is a threat to physical and mental health. The existing wellness of the individuals in the community is crucial in determining the severity of the impact of the health issues. Wellness and access to health services also contribute to the social and economic development of the community. [23] A healthy community practices healthy lifestyle and knows the functional needs of the community and this eventually have an influence on their resilience. In this context, wellness served as the resources for the community. [34-35]

The wellness of the community with lower prevalence of chronic illnesses make them to better withstand the impacts hence taking lesser time to recover and reduce resources usage.[36] Our findings showed one third of the community having chronic illness and therefore creating awareness among the individuals on the importance of health and its association with empowerment was essential. The results from this study showed chronic illness were not significantly associated with empowerment but those who experienced more health symptoms two weeks post flood showed higher intention, participation, motivation, and critical awareness. It is most probable that lessons learnt from past experience had contributed to the increase in their empowerment level.

When discussing about gender issues, the men in this study were more motivated, and participated more towards community empowerment during disasters and natural calamities as shown in another study by Najafi et al., (2015). Women in general showed less. They are considered more vulnerable and experience more negative effects than men. [27] Several factors affect their level of empowerment. Studies have shown that the process of women's empowerment is greatly influenced by the setting of the community, culture, women's marital age, size of family, number of children, flexibility and time spent for creative activities. [24] Since gender inequality still occur in most situations at home, the women counterparts are hindered to make decisions and this deprive their potential in human resource and knowledge. [26]

Although women are more engaged than men in preparing their families in cases of disaster, their involvement in formal emergency planning organizations is less. Muttarak \& Pothisiri (2013) noted that women were less empowered in disaster preparedness. However, with higher education and economic status, the empowerment increased. [24, 29] In another study, gender awareness activities have led to the empowerment in women whereby women and children attended the shelter first during the warning for cyclone Aila in May 2009. [28]

The developed community are more resilient to flood disaster due to their better preparation based on past experiences with the help of local and federal government.[20] The rural communities are always associated with poor economic status and they usually reside at the flood prone areas; for instance, such as the farmers reside near the river banks and fishermen reside near the coastal areas.[33] In many developing and underdeveloped nations, the poor have limited access to resources and inadequate infrastructure thus compromising their chances for relief programs which therefore affects their resilience. For instances, rural communities affected by flood might be left with inadequate resources to accommodate the needs of the communities due to the poverty and geographical distribution.[23] Based on our findings, staying further from health facility showed higher participation, motivation, and critical awareness. This may be due to their previous experiences with flood that had contributed towards an increase in their community empowerment. [25]

The Community Flood Management Committees established at the flood prone regions in South Asia have taken measures such as well-defined institutional structures and pre, during and post flood roles and responsibilities. This mostly attracted rural community participation. [26] Likewise, Anu Kasmel, 2011, in their study has noted the importance of empowerment among the poor through 
program participation. [19] Similarly, our findings showed higher participation among the rural community.

Several studies showed the low income people are less empowered because the low income people take longer to recover from the economic repercussions of floods. With the low income, their contribution is also less. [23] Najafi et al., 2015 , noted higher and medium income people have higher empowerment. [25] Nevertheless no significant association was seen between income and empowerment in this study.

A more homogenous community, be it in terms of socioeconomic status or ethnicity leads to greater participation in community. Those with different level of income than majority, or minority ethnic group, have poor network and are less likely to participate. [26] Respondents in this study were mainly from the Malay ethnicity thus differences between the ethnicities in Malaysia could not be compared.

Our recommendation from this study is to create awareness on empowerment and educate community on disaster preparedness focusing on the elderly and women. This is because children, the elderly and the disabled people are considered vulnerable during flood and should be given priority in the relief activities. [20] Once the community understands the importance of empowerment in mitigating the impact of flood, the effort and involvement will upsurge. Alongside their knowledge and skills on related matters make them better equipped to face the challenges and be empowered.

Secondly is to promote wellness in the community. Empowered community consists of individuals who understand the relationship between them and the community health. Pre event wellness and post flood continuity of care are essential because the vulnerable community will take longer to recover and consume more resources. Besides, it is fundamental to ensure the health services are adequate and accessible for the community to address their physical and mental problems such as psychological first aid for traumatized victims. Coaching volunteers in disaster preparedness concepts and techniques and establishing a local self-empowered and self-sustaining community to withstand the disaster is fundamental. These strategies need concerted efforts of local agencies, government and non-governmental organizations (NGO) together with the community.

\section{Conclusions}

In conclusion, low status of empowerment was documented in all the domains except for motivation and critical awareness. The association of significant risk factors varies for each domain. Our findings highlight factors such as age, rural strata, gender, education level, wellness and health access of the community influenced the different empowerment domains. Adverse impact of flood can be reduced markedly by empowering the community. Knowing the status of empowerment, its dimensions and the associated factors prior to intervention is essential for planning of an effective intervention among the community.

\section{Acknowledgements}

We gratefully acknowledge funding support from Ministry of Education Malaysia, under Floods Management Grant, year 2015 under Trans-Disciplinary Research Grant Scheme, TRGS (TRGS/1/2015/UKM/01/1), Universiti Kebangsaan Malaysia research grant GUP-2016-025 and FF-2015-359. We would also like to thank the District and Land Officers of Temerloh, Pekan and Kuantan for their cooperation and commitment in this research. Our greatest appreciation to Dean of Faculty of Medicine, National University of Malaysia and Director, Institute for Environment and Development (LESTARI), UKM for the ethical approval and permission to conduct this study.

\section{REFERENCES}

[1] Chan N. W. Impacts of disasters and disasters risk management in Malaysia: The case of floods. Economic and Welfare Impacts of Disasters in East Asia and Policy Responses, 503-551, 2012

[2] Wan Nor Azmin Sulaiman, Heshmatpoor A, Mohd Hafiz Rosli. Identification of Flood Source Areas in Pahang River Basin, Peninsular Malaysia. EnvironmentAsia 3 (Special Issue), 73-78, 2010.

[3] The Official Portal for Department of Irrigation and Drainage Malaysia (DID). Flood Preparedness Guidelines, 2011, Online available from http://www.water.gov.my/drainage flood-mainmenu-288/55?task=view \&lang=en.

[4] Aminuddin A.G, Chun K.C, Cheng S.L, Nor Azazi Z. Sungai Pahang Digital Flood Mapping: 2007 Flood. International Journal of River Basin Management, Vol. 10 (2), 139-148, 2012.

[5] Akasah, Z. A. \& Doraisamy, S. V. 2014 Malaysia flood: impacts \& factors contributing towards the restoration of damages. Journal of Scientific Research and Development 2, Vol. 2 (14), 53-59, 2015.

[6] Malaysia millennium development goals report 2015. United Nations Malaysia, Vol. 53, 2016.

[7] Perveen A, Rahmattualh K, Saima M. A, Fauziah S, Muhaamad W. Gender Based Recovery Strategies of Post Flood Victims, Evaluative Survey in Kelantan, Malaysia 2015. Mediterranean Journal of Social Sciences MCSER Publishing, Rome-Italy, Vol. 7(1), 11-16, 2016.

[8] Du W, FitzGerald G, Clark M, Hou X. Health impacts of floods. Prehosp Disaster Med., 25, 265-272, 2010.

[9] Brunkard J, Namulanda G, Ratard R. Hurricane Katrina deaths, Louisiana, 2005. Disaster Med Public Health Prep. 2, 215-223, 2008. 
[10] Haines A, Kovats R, Campbell-Lendrum D, Corvalan C. Climate change and human health: impacts, vulnerability and public health. Public Health. 120, 585-596, 2006.

[11] Ragan P, Schulte J, Nelson S, Jones K. Mortality surveillance: 2004 to 2005 Florida hurricane-related deaths. Am J Forensic Med Pathol, 29, 148-153, 2008.

[12] Fox M, Chari R, Resnick B, Burke T. Potential for Chemical Mixture Exposures and Health Risks in New Orleans Post-Hurricane Katrina. Human and Ecological Risk Assessment, 15, 831-845, 2009.

[13] Ligon B. Infectious diseases that pose specific challenges after natural disasters: a review. Seminars In Pediatric Infectious Diseases, 17, 36-45, 2006.

[14] Rahman M. S, Mohamad O. B, Zarim A. Z. Climate change: a review of its health impact and percieved awareness by the young citizens. Global journal of health science, Vol 6 (4), 34464, 2014

[15] Roger Few, Mike Ahern, Franziska Matthies, Sari Kovats. Floods, Heaths and Climate Change: A Strategic View. Tyndall Centre for Climate Change Research. Working Paper No. 63, 2014

[16] Friel S, Bowen K, Campbell-Lendrum D, Frumkin H, McMichael A.J, Rasanathan K. Climate Change, Noncommunicable Diseases, and Development: The Relationships and Common Policy Opportunities. Annual Review of Public Health, Vol. 32, 133-147, 2011.

[17] Abdullah S, Sipon S, Nazli N. N, Puwasa N H. The Relationship between Stress and Social Support among Flood Victims. Procedia - Social and Behavioral Sciences, 192, 59-64, 2015

[18] Huang P, Tan H, Liu A, Feng S, Chen M. Prediction of Posttraumatic Stress Disorder Among Adults in Flood District. BMC Public Health, 10, 207, 2010.

[19] Kasmel A., Tanggaard P. Evaluation of changes in individual community-related empowerment in community health promotion interventions in Estonia. International Journal of Environmental Research and Public Health, 8 (6), 1772-1791, 2011

[20] Rajeev M. M. Sustainability and Community Empowerment in Disaster Management, 2 (6), 207-212, 2014

[21] Asian Disaster Preparedness Center. Community Empowerment and Disaster Risk Reduction in Chittagong City. The Bangladesh Disaster Preparedness Centre (BDPC). Dhaka, Bangladesh, 2008.

[22] Hall R. Adaptive Governance Policy for Societal Resilience and Community Empowerment, Vol. 11 (12), 949-959, 2014.

[23] Chandra A, Acosta J, Stern S, Uscher-Pines L, Williams M. V, Yeung D, Garnett J. et al. Building community resilience to disasters. RAND Corporation; Santa Monica, CA, 2011.
[24] Thapa A. K., Gurung L. An Assessment of Factors Influencing Empowerment Level of Females : a Case Study of Pokhara. Economic Journal of Development Issues. 11 \& 12 (1-2), 1-8, 2010.

[25] Najafi M, Ardalan A, Akbarisari A, Noorbala A. A, Jabbari, H. Demographic Determinants of Disaster Preparedness Behaviors Amongst Tehran Inhabitants, Iran. PLoS Currents. 41-43, 2015.

[26] World Meteorological Organization (WMO). Organizing community participation for flood management: A Tool for Integrated Flood Management, 1-21, 2008.

[27] Frankenberg E, Friedman J, Gillespie T, Ingwersen N, Pynoos R, Rifai I. U, Sikoki B. Mental health in Sumatra after the tsunami. American Journal of Public Health. Vol. 98 (9), 1671-1677, 2008.

[28] Empowering communities to prepare for cyclones. International Federation of Red Cross and Red Crescent Societies. Dhaka, Bangladesh, 2009.

[29] Muttarak R. \& Pothisiri W. The Role of Education on Disaster Preparedness : Case Study of 2012 Indian Ocean Earthquakes on Thailand's Andaman Coast, Vol. 18 (4), 2013.

[30] Pandey B. H., Okazaki K. Community-based disaster management: Empowering communities to cope with disaster risks. Regional Development Dialogue. Vol. 26 (2), 52-57, 2005.

[31] Kadel P. M. Community Participation in Disaster Preparedness Planning: Japan and Nepal: A comparative Study of Nepal and Japan. Asian Disaster Reduction Center. $1-29,2011$.

[32] Wilkins A. R. National Strategy for Disaster Resilience: Building our nation's resilience to disasters, 2009.

[33] Sani G. D, Gasim M. B, Toriman M. E. Floods In Malaysia: Historical Reviews, Causes, Effects and Mitigations Approach. International Journal of Interdiciplinary Research and Innovations, Vol. 2 (4), 59-65, 2014

[34] Pfefferbaum R. L, Klomp R. W. Community Engagement, Organization, and Development for Public Health Practice: Community Resilience, Disasters, and the Public's Health. Springer Publishing Company, 275-284, 2012.

[35] US Department of Homeland Security FEMA. A Whole Community Approach to Emergency Management: Principles, Themes, and Pathways for Action, 2011, Online available from

http://www.fema.gov/media-library-data/20130726-1823-250 45-8164/pub_1 final.pdf n

[36] Aldrich N. Benson W. F. Disaster preparedness and the chronic disease needs of vulnerable older adults. Preventing chronic disease, Vol. 5 (1), A27, 2008. 